\title{
Dimethylsulfide release during macroinvertebrate grazing and its role as an activated chemical defense
}

\author{
Kathryn L. Van Alstyne*, Letise T. Houser
}

Shannon Point Marine Center, Western Washington University, 1900 Shannon Point Road, Anacortes, Washington 98221, USA

\begin{abstract}
Almost half the biogenic sulfur emitted globally originates as dimethylsulfide (DMS) in marine algae. Yet, despite its importance to climate and the global sulfur cycle, the reasons why many diverse algal taxa produce DMS remain unclear. DMS is produced when dimethylsulfoniopropionate (DMSP) is cleaved by the enzyme DMSP lyase into DMS and acrylic acid. Because acrylic acid can deter feeding by some herbivores, the production of DMSP has been postulated to be part of an antiherbivore chemical defense system, with DMS being a by-product of the production of the defensive compound acrylic acid. However, we found that DMS plays a more direct role in herbivore deterrence. Using laboratory bioassays, we demonstrated that DMS functions as a potent feeding deterrent against sea urchins Strongylocentrotus droebachiensis at a wide range of concentrations. The defensive function of DMSP cleavage is further supported by the results of a multiple-choice feeding preference assay in which we offered urchins a choice of 8 algal species. In these assays, algae containing DMSP tended to be consumed at lower rates than species that lacked it. By measuring headspace DMS concentrations during grazing, we showed that DMS is produced when urchins feed on algae containing DMSP, but not when urchins feed on algae without it. DMS production occurred while the urchins were feeding on the algae and for $18 \mathrm{~h}$ after the algae were removed, suggesting that post-ingestive processes might be playing a role in activation. These results demonstrate that DMS is produced when urchins feed on algae containing DMSP and that it functions as an herbivore deterrent, causing species that produce DMSP to be avoided by some herbivores.
\end{abstract}

KEY WORDS: Activated defense - Chemical defense · DMS · DMSP · Herbivory · Macroalgae · Sea urchins

Resale or republication not permitted without written consent of the publisher

\section{INTRODUCTION}

Dimethylsulfide (DMS) produced by marine algae is a major source of atmospheric sulfur. Marine organisms generate about half the biogenic sulfur emitted to the atmosphere annually (Bates et al. 1992), and the majority of this sulfur is produced as DMS (Andreae 1986). Because reduced sulfur compounds such as DMS are rapidly oxidized to sulfur dioxides that function as cloud condensation nuclei, the production of DMS can potentially affect climate on a global scale (Charlson et al. 1987). DMS and acrylic acid are produced as a result of the cleavage of dimethylsulfoniopropionate (DMSP) by the enzyme DMSP lyase (Cantoni \& Anderson 1956). The precursor in this reaction,
DMSP, is produced by many types of marine algae including planktonic algae, such as prymnesiophytes, dinophytes, diatoms, chrysophytes, and prasinophytes, and macroalgae, such as chlorophytes and rhodophytes (Malin \& Kirst 1997).

It is not clear why so many disparate taxa of algae living in different types of environments produce DMS. DMSP can function as an osmoregulator (Reed 1983a,b, Edwards et al. 1987, 1988) and a cryoprotectant (Karsten et al. 1996), and acrylic acid may have antibiotic effects (Sieburth 1960, 1961). However, evidence also suggests that DMS may be part of an activated chemical defense against herbivores. Activated defense systems involve the enzymatic conversion of stored precursor compounds with no or limited bio- 
logical activity into predator-deterrent defensive compounds (Paul \& Van Alstyne 1992). In phytoplankton, the release of DMS increases during zooplankton grazing (Dacey \& Wakeham 1986, Wolfe \& Steinke 1996), suggesting that grazing causes mechanical damage that activates the DMSP lyase enzyme. Strains of microalgae with higher concentrations of DMSP lyase are consumed more slowly by dinoflagellates than strains that produce low concentrations of the enzyme (Wolfe et al. 1997). This is consistent with the hypothesis that the activity of the DMSP lyase enzyme is correlated with the production of chemical feeding deterrents. Finally, acrylic acid has been shown to deter feeding by some macroinvertebrate herbivores (Van Alstyne et al. 2001). However, there is no definitive evidence that either acrylic acid or DMS are produced as a result of grazing by macroinvertebrates.

In this study, we use macroalgae and sea urchins as a model system to examine the role of DMS as a feeding deterrent. We provide the first direct evidence that DMS, which is produced when algae are physically damaged by grazing, inhibits feeding by marine herbivores, making species that produce DMS low-preference foods. Our results also suggest that the DMS produced by macroinvertebrate grazing on seaweeds can cross the air-sea boundary and may contribute to coastal atmospheric sulfur production.

\section{MATERIALS AND METHODS}

Feeding deterrence by DMS. We tested the hypothesis that DMS can function as a feeding deterrent by offering sea urchins paired pieces of seaweed-based diets with and without DMS. Artificial diets were made up as described in Van Alstyne et al. (2001), with $43.5 \mathrm{ml}$ deionized water, $1.5 \mathrm{~g}$ agar, and $5 \mathrm{~g}$ of freezedried, ground Laminaria saccharina. The agar was dissolved in water in a microwave oven for $35 \mathrm{~s}$. This mixture was then cooled to $40^{\circ} \mathrm{C}$ and the ground algae and DMS added. Control diets were the same, except they lacked DMS. Urchins were not fed for at least $1 \mathrm{wk}$ prior to the start of the experiments. Starving animals prior to the start of food preference experiments has been shown to make some animals less selective (Cronin \& Hay 1996); however, because DMS evaporates rapidly from the diets, it was necessary that the urchins were hungry enough to consume the diets rapidly, before all the DMS had evaporated.

All urchins were offered a piece of the diet with DMS and the control diet simultaneously. When half of all the diets had been eaten, the remaining pieces were weighed. Most of the urchins ate half the food within
$2 \mathrm{~h}$. If an urchin had not eaten half the food within $4 \mathrm{~h}$, the replicate was eliminated from later analyses. The total consumption of diets treated with DMS was subtracted from the total consumption of control diets, and the data analyzed with a 1-sample Student's $t$-test comparing the difference to a mean of zero. Initial DMS concentrations in the experimental diets ranged from 0.04 to $2.0 \%$ of the fresh mass (FM), and were similar to the concentrations of DMS urchins would be expected to encounter in nature (Van Alstyne et al. 2001).

Because DMS is a volatile compound, it was lost by evaporation and diffusion as the experiments were set up and run. We determined that $40 \%$ of the DMS added to the agar was lost before the diets were added to the containers. To account for this initial loss, the amount of DMS added to the agar was adjusted so that the experimental diets would contain the stated amount of DMS when the urchins were added. DMS loss also occurred during the experiments, while the urchins were feeding on the diets. To estimate this loss we placed containers holding only pieces of diet at 3 DMS concentrations, $0.1,0.5$, and $2.0 \%$ DMS, in seawater tables. These conditions were similar to those in which the feeding experiments were run except for the absence of urchins. Three pieces of diet at each of the 3 concentrations were removed at regular intervals and placed into $4 \mathrm{~N} \mathrm{NaOH}$ in gas-tight containers, to determine how much DMS remained in the diets. DMS was measured using an SRI gas chromatograph with a Chromasil 330 column and a flame photometric detector, as described in Van Alstyne et al. (2001).

Food preference experiments. To determine if algae that produce DMSP are avoided by urchins, we offered 8 species of algae in multiple-choice feeding preference assays. The algae included 3 DMSP-producing species (Enteromorpha linza, Polysiphonia hendryi, Ulva fenestrata; Van Alstyne et al. 2001), 3 species that produce other types of chemical or structural defenses (Alaria marginata, Agarum fimbriatum, and Mazzaella splendens; Gaines 1985, Steinberg 1985), and 2 species not known to produce significant quantities of anti-herbivore defenses (Laminaria saccharina and Nereocystis luetkeana).

Each urchin was offered eight $\sim 0.5 \mathrm{~g}$ pieces of nonreproductive, non-meristematic algal blade tissues in a single arena (Van Alstyne et al. 1999). Paired arenas that contained algae, but no urchins, were controls for autogenic losses. Algae were weighed at the beginning of the experiment and after urchins had consumed half of the algae in the container. Statistical analyses were conducted with a Yao's $R$-test, a multivariate method appropriate for non-independent data (Manly 1993). 
Release of DMS during grazing. To estimate the production of gaseous DMS resulting from Strongylocentrotus droebachiensis grazing, we conducted feeding experiments in $10 \mathrm{~cm}$ diameter gas-tight chambers containing rubber septa, which allowed us to sample DMS in the headspace of the chambers. Small urchins $(\sim 4 \mathrm{~cm}$ test diameter) were each placed in 8 replicate chambers with a piece of algae (0.6 to $0.7 \mathrm{~g})$, and allowed to feed for $6 \mathrm{~h}$. After $3 \mathrm{~h}$ and $6 \mathrm{~h}$, DMS concentrations were measured in the headspace of the containers using solid phase microextraction with $75 \mu \mathrm{m}$ carboxen-PDMS fibers (absorption: 10 to $30 \mathrm{~s}$, desorption: $10 \mathrm{~s}, 250^{\circ} \mathrm{C}$ ) in an SRI gas chromatograph (Chromasil 330 column, flame photometric detector). After $6 \mathrm{~h}$, the algae were removed, and the chambers, still containing the urchins, were resealed. DMS production was measured again after 18, 42, and $66 \mathrm{~h}$. After each measurement, the seawater in the container was replaced to ensure that the urchins had adequate oxygen. Four additional chambers in each experiment contained seawater and algae but no urchins, and 4 chambers contained only seawater, with known amounts of DMS. The experiments were conducted with 3 species of algae that produce DMSP (Enteromorpha linza, Polysiphonia hendryi, and Ulva fenestrata) and 3 species that do not (Nereocystis luetkeana, Mazzaella splendens, and Laminaria saccharina; Table 1). Statistical analyses were conducted with $t$-tests comparing the total amount of DMS generated over $72 \mathrm{~h}$. Each replicate was normalized by the mass of the algal piece in the container.

To confirm that the algae used in these experiments contained the amounts of DMSP we expected, we conducted DMSP measurements from 8 replicate pieces of each species. DMSP was measured as DMS by placing algae ( 100 mg) into $4 \mathrm{~N} \mathrm{NaOH}$ in gas-tight vials. After $24 \mathrm{~h}, \mathrm{DMS}$ concentrations in the headspaces were measured by direct injection with an SRI gas chromatograph.

Table 1. DMSP concentrations from algae used in food preference and DMS release assays. Data are given as means $\pm 1 \mathrm{SD}$ $(\mathrm{n}=8)$

\begin{tabular}{|lc|}
\hline \multicolumn{1}{|c|}{$\begin{array}{c}\text { DMSP concentration } \\
\text { (\% of fresh mass) }\end{array}$} \\
\hline Species with high DMSP concentrations \\
Enteromorpha linza (Chlorophyta) & $1.22 \pm 0.11$ \\
Polysiphonia hendryi (Rhodophyta) & $0.26 \pm 0.01$ \\
Ulva fenestrata (Chlorophyta) & $1.55 \pm 0.11$ \\
Species with low DMSP concentrations & \\
Laminaria saccharina (Phaeophyta) & $0.00 \pm 0.00$ \\
Mazzaella splendens (Rhodophyta) & $0.00 \pm 0.00$ \\
Nereocystis luetkeana (Phaeophyta) & $0.00 \pm 0.00$ \\
\hline
\end{tabular}

\section{RESULTS}

When sea urchins were offered choices of control diets without DMS and identical diets containing DMS, they consumed more of the control diets, regardless of the DMS concentration in the diet (Fig. 1). In many of the experimental arenas, urchins pushed away the pieces of diet containing DMS with their tube feet, while retaining and feeding upon the control diets. During the feeding experiments, significant amounts of DMS were lost in the experimental diets. Most of the diets lost about $50 \%$ of the DMS within $1 \mathrm{~h}$ and $75 \%$ within $4 \mathrm{~h}$ (Fig. 2). Thus, as the experiment progressed, the urchins were making choices between diets with relatively smaller differences in DMS concentrations, making the experiments conservative for the effects of DMS on food preferences.

In the multiple-choice feeding preference experiments in which urchins were given a choice of 8 algal species, urchins consumed algae containing DMSP at the same or lower rates as other chemically or structurally defended algae (Fig. 3). The 2 DMSP-producing green algae, Enteromorpha linza and Ulva fenestrata, were among the 3 least-preferred algae. Feeding rates on another DMSP-producing species, Polysiphonia hendryi, were intermediate, but were comparable to feeding rates on Alaria marginata, a brown alga that contains relatively high concentrations of phlorotannins (Steinberg 1984). Feeding rates were highest on the 2 species that produce low quantities of phlorotannins, Nereocystis luetkeana and Laminaria saccharina.

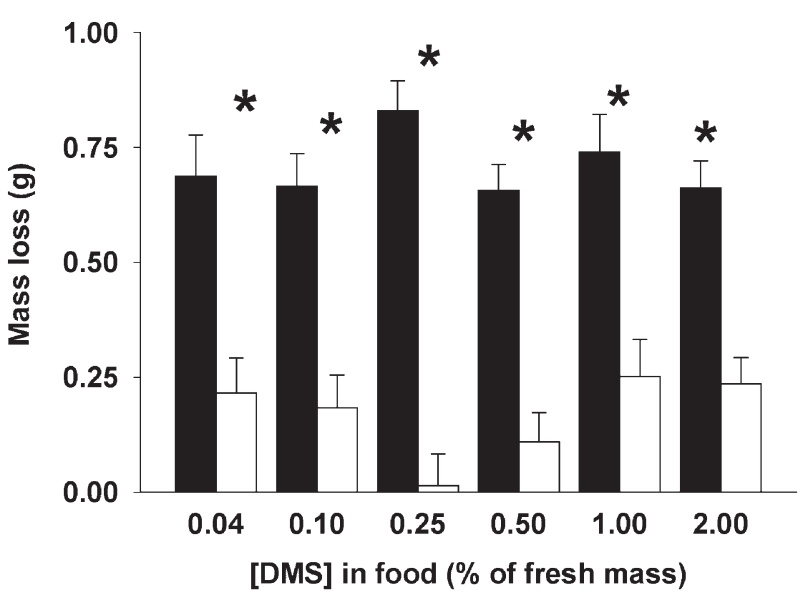

Fig. 1. Strongylocentrotus droebachiensis. Consumption rates (means $\pm 1 \mathrm{SE}$ ) of diets. Urchins were offered choices of control diets (black bars) and diets containing DMS (white bars). Concentrations of DMS in the diets at the beginning of each experiment are given below each set of bars. Asterisks indicate experiments in which consumption rates differed significantly between control diets and diets with DMS ( $\mathrm{p}<0.05,1$-sample $t$-test) 
When urchins fed upon algae containing DMSP, DMS was released and accumulated in the headspace of the containers during the $6 \mathrm{~h}$ that the urchins had access to the algae (Fig. 4). DMS continued to accumulate during the $18 \mathrm{~h}$ period after the algae were removed, suggesting that post-ingestive processes

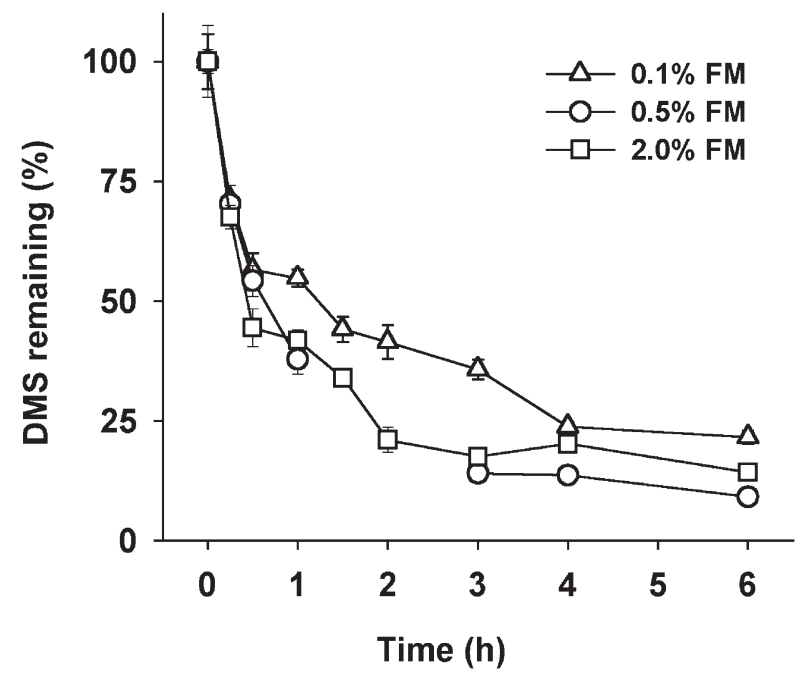

Fig. 2. DMS loss in diets at 3 initial DMS concentrations over $6 \mathrm{~h}$. Data are means $\pm 1 \mathrm{SD}(\mathrm{n}=3)$. FM: fresh mass

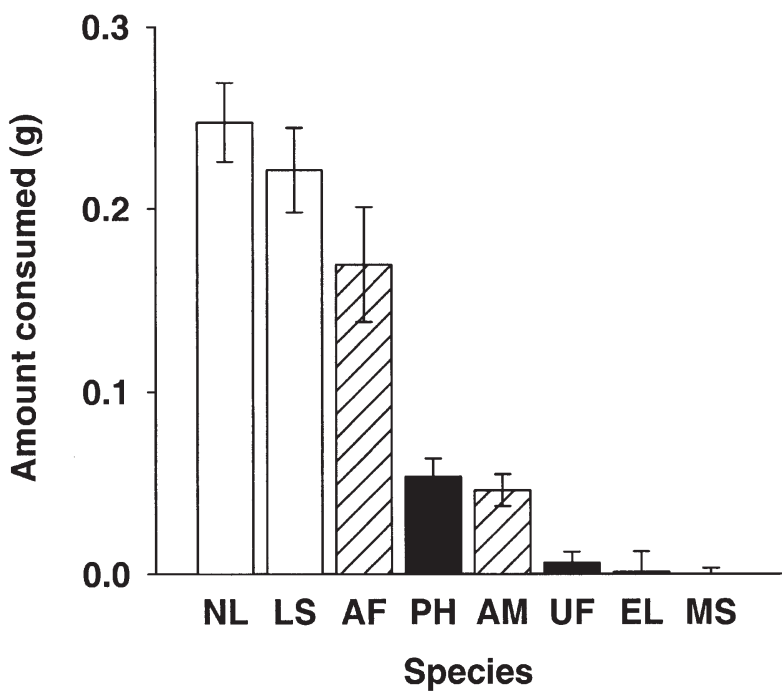

Fig. 3. Strongylocentrotus droebachiensis. Consumption rates (means $\pm 1 \mathrm{SE}$ ) of macroalgae in multiple-choice feedingpreference experiments. Black bars indicate species that produce DMSP, hatched bars indicate species that produce other chemical or structural defenses, and white bars indicate species that are not known to produce significant chemical or structural defenses. Feeding rates among algae are significantly different (Yao's $R=5.722, \mathrm{p}=0.013$ ). NL: Nereocystis luetkeana, LS: Laminaria saccharina, AF: Agarum fimbriatum, PH: Polysiphonia hendryi, AM: Alaria marginata, UF: Ulva fenestrata, EL: Enteromorpha linza, MS: Mazzaella splendens contribute to DMS production in the herbivores' guts. DMS was not detectable in the chambers when urchins fed upon algae that do not produce DMSP (Fig. 4). Similarly, little or no DMS was produced by seawater alone, seawater and algae alone, or seawater and urchins alone.

There were significant differences in total amounts of DMS generated in arenas with and without herbivores for the 3 DMSP-producing algae, Enteromorpha linza $(t=5.394, p=0.001)$, Polysiphonia hendryi $(t=11.526, \mathrm{p}<0.001)$, and Ulva fenestrata $(t=2.637$, $\mathrm{p}=0.034)$. There was no significant difference in DMS production between containers with and without herbivores when Nereocystis luetkeana was in the containers $(t=1.487, \mathrm{p}=0.180)$. No DMS was measurable in any of the arenas holding Laminaria saccharina or Mazzaella splendens, regardless of the presence or absence of herbivores, so statistical analyses could not be performed on these data.

\section{DISCUSSION}

The results of this study demonstrate that the DMS produced during grazing by macroinvertebrates can function as a feeding inhibitor. Even at very low concentrations (0.04\% FM), diets containing DMS were avoided relative to diets that lacked it (Fig. 1). Because a significant amount of DMS was lost during the experiments (Fig. 2), urchins may have been making choices when the diets contained less DMS than they

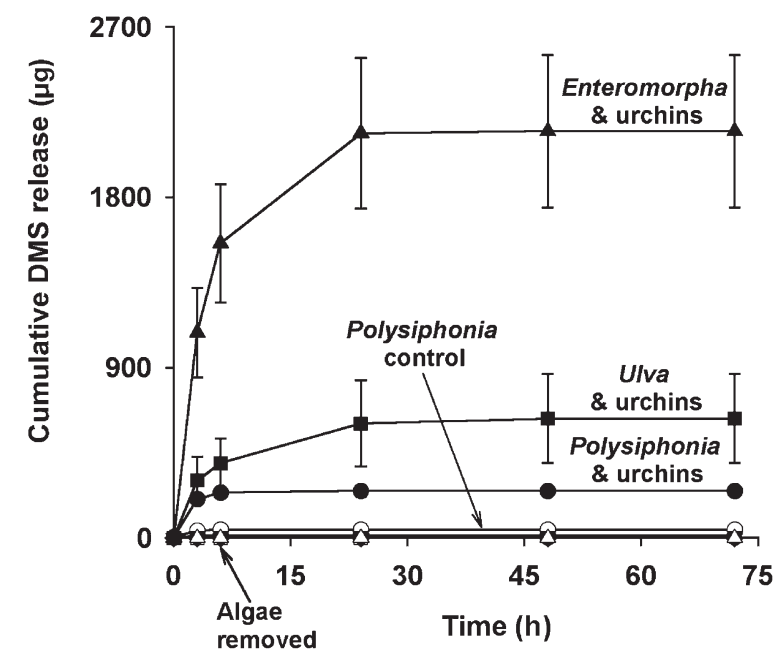

Fig. 4. Strongylocentrotus droebachiensis. DMS release (means $\pm 1 \mathrm{SE}$ ) during feeding. Three species of macroalgae contained

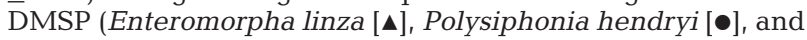
Ulva fenestrata [ $\mathbf{\square}]$ ), and 3 lacked it (Laminaria saccharina [ $\mathbf{\nabla}]$, Mazzaella splendens [ $\bullet$ ] and Nereocystis luetkeana [ $\bullet$ ]). Control arenas contained algae but no urchins $(E$. linza $[\Delta], L$. saCCharina $[\nabla], M$. splendens $[\triangleright], N$. luetkeana $[\diamond], P$. hendryi $[0]$, $U$. fenestrata [ㅁ]) 
did at the beginning of the experiment. Thus, the ability of DMS to deter feeding may be present at lower concentrations than the ones we tested.

The concentrations of DMS tested in our experiments were within the range that is expected to be produced during DMSP cleavage. Temperate macroalgae that produce DMSP can contain 0.1 to $\sim 1.7 \%$ FM DMSP (White 1982, Reed 1983a, Karsten et al. 1990, Van Alstyne et al. 2001); in the Ulvales, average concentrations that exceed 1\% FM are common. Because cleavage results in the production of 2 similarly sized molecules, DMS and acrylic acid, the maximum amount of DMS by weight that can be produced during cleavage will be about half the initial DMSP concentration. Thus, for many algae, if only part of the DMSP present is cleaved into DMS and acrylic acid, the DMS concentrations should still be sufficient to deter urchins from grazing. Furthermore, acrylic acid is also a feeding deterrent towards urchins at concentrations as low as 0.1\% FM (Van Alstyne et al. 2001). Although DMS and acrylic acid have not been tested together as feeding deterrents, it is likely that the combination of DMS and acrylic acid will be a more potent feeding deterrent than DMS alone. This suggests that the DMSP-activated defense system is highly effective against herbivores such as urchins.

The evidence for an ecological role for DMS is further supported by the results of the multiple-choice food-preference experiment (Fig. 3). Seaweeds containing DMSP, such as Polysiphonia hendryi, Enteromorpha linza, and Ulva fenestrata, were low- to intermediate-preference foods, avoided even when urchins were offered a choice between these species and other chemically or morphologically defended algae. Preferences were lowest for the ulvoid green algae E. linza and $U$. fenestrata, species that produce DMSP, and Mazzaella splendens, a red alga that does not produce DMSP. M. splendens produces an outer cuticle that slows feeding by isopods but not sea urchins (Gaines 1985). Thus, the low preference for M. splendens by urchins likely results from an unknown chemical defense.

Feeding rates on the third DMSP-producing alga, Polysiphonia hendryi, were intermediate and comparable to those on Alaria marginata. However, we may have overestimated the tissue loss for $P$. hendryi. Because urchins tend to shred this alga when they handle it, some loss may have occurred when small pieces of intact algae washed through the screens of the containers. A. marginata is a phaeophyte that produces phlorotannins (Steinberg 1984) in sufficient concentrations to deter feeding by urchins (Steinberg et al. 1995). It was the only low or intermediate preference alga used in these experiments that is known to produce significant quantities of chemical defenses other than DMSP.
Herbivore deterrence may be a common function of DMSP and DMS among many diverse groups of algae. Although DMSP is thought to be involved in osmoregulation and cryoprotection (Reed 1983a,b,c, Edwards et al. 1987, 1988, Kirst 1989, Karsten et al. 1990, 1996, Kirst et al. 1991), many species that produce it, particularly open-ocean phytoplankton, are unlikely to experience large fluctuations in salinity or temperature. Moreover, the use of DMSP in cryoprotection and osmoregulation does not address the reason for having an additional pathway to convert DMSP to DMS. However, both macroalgae and microalgae can experience significant grazing pressures (Hawkins \& Hartnoll 1983, Hay 1991, Banse 1996, Sommer 1996), and thus may benefit from using DMS as a feeding deterrent.

The use of DMS and DMSP in an activated antiherbivore defense does not rule out other functions for these compounds, nor does it suggest that these compounds function as defenses against all consumers. Like many marine secondary metabolites, these compounds probably have multiple functions (Schmitt et al. 1995, Kubanek et al. 2002) and affect some consumers but not others (Hay et al. 1987, Steinberg \& van Altena 1992). For example, DMS has no effect on feeding by a generalist predatory fish, Thalassoma bifasciatum, even at concentrations that are 10 to 100 times higher than those found in sponges, a potential prey of the fish (Pawlik et al. 2002).

Several examples of putative activated defenses have been described in seaweeds (Paul \& Van Alstyne 1992, Cetrulo \& Hay 2000). However, none of these studies have demonstrated that the products of activation are actually generated during the consumption of the algae. In this study, we have demonstrated that one of the products of activation, DMS, is produced when algae are grazed by sea urchins (Fig. 4). Significant DMS release only occurred after urchins ate algae containing DMSP and did not occur during grazing on algae without DMSP. This suggests that the DMS that was produced during grazing originated from the algae rather than the urchins.

Previous studies have assumed that the activation of chemical defenses in marine algae occurs when the plants are masticated by herbivores (Paul \& Van Alstyne 1992). However, data from our urchin-grazing experiments suggest that post-ingestive processes also cause the release of the products. During our grazing experiments, most of the DMS generation occurred during the first $6 \mathrm{~h}$ of the experiment, when the urchins had access to the algae, but some DMS was generated after the algae were removed from the containers. Since the only likely source of DMS was DMSP from undigested seaweeds in the guts of the urchins, the DMS generated after the removal of the algae was 
probably produced by DMSP cleavage during digestion. The DMS produced during the initial $6 \mathrm{~h}$ of the experiment may also have resulted from the digestive breakdown of DMSP since urchins typically bite off and ingest large pieces of intact algae with the teeth of their Aristotle's lanterns, and lack a mechanism for masticating their food thoroughly.

Although there are many studies of DMS release by planktonic microalgae (Bates et al. 1992, Malin et al. 1992, Malin \& Kirst 1997), there is relatively little information about the amounts of DMS released by coastal macroalgae. DMS production in the oceans is generally higher in tropical than temperate regions and varies seasonally (Bates et al. 1992). Coastal waters have higher production rates of DMS than oceanic waters (Turner et al. 1988) but because of their limited area are responsible for a relatively small proportion of the global production of DMS (Bates et al. 1990). Estimates of nearshore DMS production rates, which would include DMS generated by macroalgae, are rarely made. Our study shows that DMS release as a result of macroinvertebrate grazing on macroalgae may be a source of atmospheric DMS that has not previously been considered. However, like coastal planktonic DMS production, any contributions to atmospheric sulfur concentrations are likely to be very localized and play a limited role in global sulfur cycling.

Macroinvertebrate-macroalgal interactions involving DMS show many similarities to the microzooplankton-phytoplankton interactions that result in DMS release in the open oceans. Macroalgae producing DMSP are avoided by sea urchins (Fig. 3). Microherbivores avoid strains of microalgae with high DMSP lyase activity (Wolfe et al. 1997). The release of DMS into the atmosphere is enhanced by grazing of both macroalgae (Fig. 4) and phytoplankton (Dacey \& Wakeham 1986, Wolfe \& Steinke 1996). These similarities suggest that the use of DMS as an herbivore deterrent could span a range of algal sizes, taxa, and habitats. Having a greater understanding of the role of DMS in ecological interactions in coastal and open ocean environments will enable better predictions of DMS production, and may ultimately lead to a better understanding of the role of biogenic factors in sulfur cycling and climate change.

Acknowledgements. We are grateful to S. Caldwell for assistance with feeding experiments, D. Cancilla, K. Bright, and G. Wolfe for advice on solid phase microextraction and gas chromatography, J. Mullen for constructing urchin containers, and B. Bingham and E. Marmol for comments on this manuscript. Funding was provided by an NSF grant to KLV (IBN-0090825) and an NSF Minorities in Marine Sciences for Undergraduates Program grant (OCE-9729316) to Shannon Point Marine Center.

\section{LITERATURE CITED}

Andreae MO (1986) The ocean as a source of atmospheric sulfur compounds. In: Buat-Menard P (ed) The role of air-sea exchange in geochemical cycling. Reidel, Dordrecht, p 331-362

Banse K (1996) Low seasonality of low concentrations of surface chlorophyll in the subantarctic water ring: underwater irradiance, iron, or grazing? Prog Oceanogr 37: 241-291

Bates TS, Johnson JE, Quinn PK, Goldan PD, Kuster WC, Covert DC, Hahn CJ (1990) The biogeochemical sulfur cycle in the marine boundary layer over the northeast Pacific Ocean. J Atmos Chem 10:59-81

Bates TS, Lamb BK, Guenther A, Dignon J, Stoiber RE (1992) Sulfur emissions to the atmosphere from natural sources. J Atmos Chem 14:315-337

Cantoni GL, Anderson DG (1956) Enzymatic cleavage of dimethylpropiothetin by Polysiphonia lanosa. J Biol Chem 222:171-177

Cetrulo GL, Hay ME (2000) Activated chemical defenses in tropical versus temperate seaweeds. Mar Ecol Prog Ser 207:243-253

Charlson RJ, Lovelock JE, Andreae MO, Warren SG (1987) Oceanic phytoplankton, atmospheric sulphur, cloud albedo and climate. Nature 326:655-661

Cronin G, Hay ME (1996) Susceptibility to herbivores depends on recent history of both the plant and animal. Ecology 77:1531-1543

Dacey JWH, Wakeham SG (1986) Oceanic dimethylsulfide: production during zooplankton grazing on phytoplankton. Science 233:1314-1316

Edwards DM, Reed RH, Chudeck JA, Foster R, Stewart WDP (1987) Organic solute concentration in osmoticallystressed Enteromorpha intestinalis. Mar Biol 95:583-592

Edwards DM, Reed RH, Stewart WDP (1988) Osmoacclimation in Enteromorpha intestinalis: long-term effects of osmotic stress on organic solute concentration. Mar Biol 98:467-476

Gaines SD (1985) Herbivory and between-habitat diversity: the differential effectiveness of defenses in a marine plant. Ecology 66:473-485

Hawkins SJ, Hartnoll RG (1983) Grazing of intertidal algae by marine invertebrates. Oceanogr Mar Biol Annu Rev 21: $195-282$

Hay ME (1991) Fish-seaweed interactions on coral reefs: effects of herbivorous fishes and adaptations of their prey. In: Sale PF (ed) The ecology of fishes on coral reefs. Academic Press, San Diego, p 96-119

Hay ME, Fenical W, Gustafson K (1987) Chemical defense against diverse coral-reef herbivores. Ecology 68:1581-1591

Karsten U, Wiencke C, Kirst GO (1990) Dimethylsulfoniopropionate (DMSP) accumulation in green macroalgae from polar to temperate regions: interactive effects of light versus salinity and light versus temperature. Polar Biol 12:603-607

Karsten U, Kück K, Vogt C, Kirst GO (1996) Dimethylsulfoniopropionate production in phototrophic organisms and its physiological function as a cryoprotectant. In: Kiene RP, Visscher RP, Keller MD, Kirst GO (eds) Biological and environmental chemistry of DMSP and related sulfonium compounds. Plenum Press, New York, p 143-153

Kirst GO (1989) Salinity tolerance of eucaryotic marine algae. Annu Rev Plant Physiol Plant Mol Biol 40:21-53

Kirst GO, Thiel C, Wolff H, Nothnagel J, Wanzek M, Ulmke R (1991) Dimethylsulfoniopropionate (DMSP) in ice-algae and its possible biological role. Mar Chem 35:381-388 
Kubanek J, Whalen KE, Engel S, Kelly SR, Henkel TP, Fenical W, Pawlik JR (2002) Multiple defensive roles for triterpene glycosides from two Caribbean sponges. Oecologia 131: 125-136

Malin G, Kirst GO (1997) Algal production of dimethylsulfide and its atmospheric role. J Phycol 33:889-896

Malin G, Turner SM, Liss PS (1992) Sulfur: the plankton/ climate connection. J Phycol 28:590-597

Manly BJF (1993) Comments on the design and analysis of multiple-choice feeding-preference experiments. Oecologia 93:149-152

Paul VJ, Van Alstyne KL (1992) Activation of chemical defenses in the tropical green algae Halimeda spp. J Exp Mar Biol Ecol 160:191-203

Pawlik JR, McFall G, Zea S (2002) Does the odor from sponges of the genus Ircinia protect them from fish predators? J Chem Ecol 28:1103-1115

Reed RH (1983a) Measurement and osmotic significance of dimethylsulphoniopropionate in marine macroalgae. Mar Biol Lett 4:173-181

Reed RH (1983b) The osmotic significance of tertiary sulphonium and quaternary ammonium compounds in marine macroalgae. Br Phycol J 18:208

Reed RH (1983c) The osmotic responses of Polysiphonia lanosa (L.) Tandy from marine and estuarine sites: evidence for incomplete recovery of turgor. J Exp Mar Biol Ecol 68:169-193

Schmitt TM, Hay ME, Lindquist N (1995) Constraints on chemically mediated coevolution: multiple functions for seaweed secondary metabolites. Ecology 76:107-123

Sieburth JM (1960) Acrylic acid, an 'antibiotic' principle in Phaeocystis blooms in Antarctic waters. Science 132: 676-677

Editorial responsibility: Charles Birkeland (Contributing Editor), Honolulu, Hawaii, USA
Sieburth JM (1961) Antibiotic properties of acrylic acid, a factor in the gastrointestinal antibiosis of polar marine animals. J Bacteriol 82:72-79

Sommer U (1996) Plankton ecology: the past two decades of progress. Naturwissenschaften 63:293-301

Steinberg PD (1984) Algal chemical defenses against herbivores: allocation of phenolic compounds in the kelp Alaria marginata. Science 223:405-407

Steinberg PD (1985) Feeding preferences of Tegula funebralis and chemical defenses of marine brown algae. Ecol Monogr 55:333-349

Steinberg PD, van Altena I (1992) Tolerance of marine invertebrate herbivores to brown algal phlorotannins in temperate Australia. Ecol Monogr 62:189-222

Turner SM, Malin G, Liss PS, Harbour DS, Holligan PM (1988) The seasonal variation of dimethylsulfide and dimethylsulphoniopropionate concentrations in nearshore waters. Limnol Oceanogr 33:364-375

Van Alstyne KL, Ehlig JM, Whitman SL (1999) Feeding preferences for juvenile and adult algae depend on algal stage and herbivore species. Mar Ecol Prog Ser 180:179-185

Van Alstyne KL, Wolfe GV, Friedenberg TL, Neill A, Hicken C (2001) Activated defense systems in marine macroalgae: an ecological role for DMSP cleavage. Mar Ecol Prog Ser 213:53-65

White RH (1982) Analysis of dimethylsulfonium compounds in marine algae. J Mar Res 40:529-536

Wolfe GV, Steinke M (1996) Grazing-activated production of dimethylsulfide (DMS) by two clones of Emiliania huxleyi. Limnol Oceanogr 41:1151-1160

Wolfe GV, Steinke M, Kirst GO (1997) Grazing-activated chemical defense in a unicellular marine alga. Nature 387: 894-897

Submitted: May 20, 2002; Accepted: January 8, 2003

Proofs received from author(s): February 28, 2003 